\title{
Wheezing Phenotypes in Childhood - Is it Already Asthma?
}

\author{
Mário Morais-Almeida ${ }^{1,2}$ and Helena Pité ${ }^{3,4}$
}

1. Head of the Allergy Center, CUF Descobertas Hospital and CUF Infante Santo Hospital, Lisbon, Portugal; 2. CINTESIS - Center for Research in Health Technologies and Information Systems - Faculty of Medicine, University of Porto, Porto, Portugal; 3. Specialist in Immunoallergy, Allergy Center, CUF Descobertas and CuF Infante Santo Hospital, Lisbon, Portugal; 4. PhD Student, CEDOC, Chronic Diseases Research Center, NOVA Medical School/Faculdade de Ciências Médicas, Universidade Nova de Lisboa, Lisbon, Portugal

\begin{abstract}
Wheezing in early childhood is common but highly heterogeneous. Distinguishing early wheeze phenotypes to predict long-term asthma persistence is of major clinical relevance. The comprehensive analysis of longitudinal datasets, including novel 'unbiased' statistical approaches to detect clusters from objective data, may allow better comparisons in different population settings. The recognition of such distinct outcome groups is valuable for parents' informed counselling and a prerequisite for phenotype-specific tailored interventional measures to reduce asthma burden from paediatric age until adulthood.
\end{abstract}

\section{Keywords}

Asthma, cluster, phenotype, prognosis, wheezing

Disclosure: Mário Morais-Almeida and Helena Pité have no conflicts of interest to declare. No funding was received for the publication of this article.

Open Access: This article is published under the Creative Commons Attribution Noncommercial License, which permits any non-commercial use, distribution, adaptation and reproduction provided the original author(s) and source are given appropriate credit.

Received: 12 June 2015 Published Online: 17 August 2015 Citation: European Respiratory and Pulmonary Diseases, 2015;1(1):14-5 DOI: 10.17925/ERPD.2015.01.01.14 Correspondence: Mário Morais-Almeida, Allergy Center, CUF-Descobertas Hospital, 1998-018 Lisbon, Portugal. E: mmoraisalmeida@netcabo.pt

Wheezing in early childhood is among the most frequent respiratory symptoms. Despite its common occurrence, many children with early wheeze become symptom-free in later childhood and adolescence. However, early onset of recurrent wheeze is also associated with persistent asthma into adulthood, as well as to more severe, persistent lung function impairment. ${ }^{1-4}$ This illustrates the heterogeneity of wheezing episodes in early childhood. Distinguishing different early childhood wheeze phenotypes is internationally recognised as an unmet need, since aetiology, pathophysiology, best therapy and outcome may differ.

The largest contributions to identify early childhood wheeze phenotypes came from longitudinal birth-cohort studies. The Tucson Children's Respiratory Study was one of the most relevant birth cohort studies, designed to determine wheeze risk factors. ${ }^{5} A$ total of 1,246 new-borns were recruited and the cohort reflected a general population sample. Three phenotypes were defined: persistent wheeze (with onset $<3$ years of age and persisting at 6 years), late-onset wheeze (absent at the age of 3 but present at 6 years) and transient-early wheeze (onset $<3$ years of age but absent at 6 years). Thereafter, classifications with two to six phenotypes have been proposed, based on distinct long-term large cohort studies. ${ }^{6-10}$ However, most of these phenotypic classifications had been limited to single disease dimensions, subjectively defined based on directly observable characteristics or a priori defined hypothesis. This originated distinct classifications, which are hardly comparable. Its application to different age groups or incorporation of other characteristics is restrained. Furthermore, phenotype classifications based on temporal criteria have a limited clinical use, since such groups can only be established retrospectively. In clinical practice, it may be difficult to categorise many children into mutually exclusive groups and phenotypes are not consistent over time. Currently, the relation between the different childhood wheeze phenotype definitions is not clear and no consensual classification exists. ${ }^{1}$ Despite these difficulties, reliable phenotype definitions are important both for research and clinical practice. In this regard, wheeze phenotype definitions are valuable for informed counselling of parents and a prerequisite for the desirable phenotypic-specific or tailored treatment.

In more recent years, statistical methods that can account for multiple disease dimensions have been proposed to facilitate the unbiased identification of relevant phenotypes. ${ }^{11}$ Such groups may not be directly observable and must be determined from objective data. Statistical methods designed to detect clusters underlying multivariable data have the advantage of avoiding the need to define phenotypes by the onset of wheeze at a given age or other pre-specified criteria. Another benefit is to simultaneously consider several disease dimensions. These methods tend to have a broader application, better allowing comparisons in different population settings. Though less biased, unsupervised cluster analysis remains dependent on the collected variables, which are still selected by the investigator. In order to improve childhood wheeze classification, the time dimension needs to be taken into account, to cope with the recognised instability of asthma characteristics in children. The wealth of data from longitudinal datasets requires the application of flexible mathematical approaches to model the effects of time-varying factors (namely environmental exposures) and wheeze outcomes with multiple trajectories, measured at different time points.

Children with poor wheezing prognosis, with regard to asthma later in life and use of preventive treatment, are mostly atopic and have personal history of rhinitis and/or eczema in pre-school age. ${ }^{12-16}$ This supports that recurrent wheezing in early childhood associated with allergen sensitisation has a poorer prognosis, especially when 
multiple early sensitisations occur. This reinforces the need to identify and quantify atopic sensitisations in early ages by in vivo or in vitro tests. Moreover, it has been shown that the reduction of exposure to multiple allergens decreased the likelihood of current asthma diagnosis by half, in children at high risk for this disease. ${ }^{17}$ Allergen sensitisation should strengthen the diagnosis of asthma, while interventions to reduce allergen exposure may be associated with a more favourable prognosis.

Rhinitis is an independent risk factor for asthma in children and adults and it is frequently associated with atopy in children. ${ }^{18,19}$ The association between rhinitis and asthma severity and/or control has been documented, including in children. ${ }^{19}$ Pre-school eczema was also strongly associated with asthma persistence. ${ }^{16}$
Parental history of asthma in wheezing children was associated with persistent asthma, although some studies have suggested that maternal and paternal characteristics may have a distinct impact in their offspring asthma development. ${ }^{20}$ Epigenetic changes due to environmental exposures during pregnancy or breastfeeding may account for some of these differences; exposure to tobacco smoke can also be important.

In brief, 'unbiased' phenotypic classifications derived exclusively from data are complementary to groups defined a priori or based on directly observable criteria. The identification and characterisation of distinct wheezing phenotypes with different prognosis, by the comprehensive analysis of longitudinal datasets will allow the institution of interventional measures to reduce the asthma burden from paediatric age till adulthood.
1. Brand PL, Caudri D, Eber E, et al., Classification and pharmacological treatment of preschool wheezing: changes since 2008, Eur Respir J, 2014;43:1172-7.

2. Spycher BD, Silverman M, Kuehni CE, Phenotypes of childhood asthma: are they real?, Clin Exp Allergy, 2010;40:1130-41.

3. Guilbert TW, Mauger DT, Lemanske RF Jr, Childhood asthma-predictive phenotype, J Allergy Clin Immunol Pract, 2014;2:664-70.

4. Just J, Saint Pierre P, Amat F, et al., What lessons can be learned about asthma phenotypes in children from cohort studies?, Pediatr Allergy Immunol, 2015;26:300-5.

5. Martinez FD, Wright AL, Taussig LM, et al., Asthma and wheezing in the first six years of life. The Group Health Medical Associates, N Engl J Med, 1995;332:133-8.

6. Henderson J, Granell R, Heron J, et al., Associations of wheezing phenotypes in the first 6 years of life with atopy, lung function and airway responsiveness in mid-childhood, Thorax, 2008;63:974-80.

7. Savenije $O E$, Granell R, Caudri D, et al., Comparison of childhood wheezing phenotypes in 2 birth cohorts. ALSPAC and PIAMA, J Allergy Clin Immunol, 2011;127:1505-12. 8. Phelan PD, Robertson CF, Olinsky A, The Melbourne Asthma Study: 1964-1999, J Allergy Clin Immunol, 2002;109:189-94.

9. Turner SW, Palmer $\mathrm{L}$, Rye PJ, et al., The relationship between infant airway function, childhood airway responsiveness, and asthma, Am J Respir Crit Care Med, 2004;169:921-7.

10. Palmer $\amalg$, Rye PJ, Gibson NA, et al., Airway responsiveness in early infancy predicts asthma, lung function, and respiratory symptoms by school age, Am $」$ Respir Crit Care Med, 2001:163:37-42.

11. Wardlaw AJ, Silverman $M$, Siva R, et al., Multi-dimensional phenotyping: towards a new taxonomy for airway disease Clin Exp Allergy, 2005;35:1254-62.

12. Spycher BD, Silverman M, Brooke AM, et al., Distinguishing phenotypes of childhood wheeze and cough using latent class analysis, Eur Respir J, 2008;31:974-81.

13. Morgan WJ, Stern DA, Sherrill DL, et al., Outcome of asthma and wheezing in the first 6 years of life: follow-up through adolescence, Am I Respir Crit Care Med, 2005:172:1253-8.

14. Ross S, Godden DJ, Abdalla M, et al, Outcome of wheeze in childhood: the influence of atopy, Eur Respir J, 1995;8:2081-7.

15. Simpson A, Tan VY, Winn J, et al., Beyond atopy: multiple patterns of sensitization in relation to asthma in a birth cohort study, Am J Respir Crit Care Med, 2010;181:1200-6.

16. Morais-Almeida M, Gaspar A, Pires G, et al., Risk factors for asthma symptoms at school age: an 8 -year prospective study Allergy Asthma Proc, 2007;28:183-9.

17. Maas T, Kaper J, Sheikh A, et al., Mono and multifaceted inhalant and/or food allergen reduction interventions for preventing asthma in children at high risk of developing asthma, Cochrane Database Syst Rev, 2009;CD006480.

18. Rochat MK, Illi S, Ege MJ, et al., Allergic rhinitis as a predictor for wheezing onset in school-aged children, J Allergy Clin Immunol, 2010;126:1170-5.

19. Morais-Almeida M, Santos N, Pereira AM, et al., Prevalence and classification of rhinitis in preschool children in Portugal: a nationwide study, Allergy, 2013;68:1278-88.

20. Wu CC, Chen RF, Kuo HC, Different implications of paternal and maternal atopy for perinatal IgE production and asthm development, Clin Dev Immunol, 2012;2012:132142. 